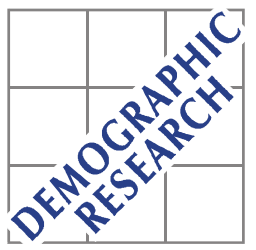

Demographic Research a free, expedited, online journal

of peer-reviewed research and commentary in the population sciences published by the Max Planck Institute for Demographic Research

Konrad-Zuse Str. 1, D-18057 Rostock · GERMANY

www.demographic-research.org

DEMOGRAPHIC RESEARCH

VOLUME 18, ARTICLE 18, PAGES 499-530

PUBLISHED 17 JUNE 2008

http://www.demographic-research.org/Volumes/Vol18/18/

DOI: $10.4054 /$ DemRes.2008.18.18

Research Article

"I didn't write the questions!"

Negotiating telephone-survey questions

on birth timing

Marian May

(C) 2008 May.

This open-access work is published under the terms of the Creative Commons Attribution NonCommercial License 2.0 Germany, which permits use, reproduction \& distribution in any medium for non-commercial purposes, provided the original author(s) and source are given credit.

See http:// creativecommons.org/licenses/by-nc/2.0/de/ 


\section{Table of Contents}

1 Introduction $\quad 500$

$2 \quad$ WOC survey data $\quad 501$

$3 \quad$ Survey interviews as interaction 503

$4 \quad$ NLC Question $167 \quad 506$

$5 \quad$ Troubled interaction in the WOC interviews 507

6 Conclusion $\quad 521$

$7 \quad$ Acknowledgements 523

References $\quad 524$

Appendix: Transcription conventions $\quad 530$ 


\title{
"I didn't write the questions!" Negotiating telephone-survey questions on birth timing
}

\author{
Marian May
}

\begin{abstract}
This paper examines interviewer-respondent interaction in the collection of demographic data where interviewer and respondents speak the same first language. Conversation analysis (CA), or the analysis of talk in interaction, makes transparent the interaction between an interviewer and 25 respondents on a question about pregnancy and birth timing in an Australian telephone survey, Negotiating the Life Course. The analysis focuses on the troubles that occur and the work that interviewers do to fit respondents' answers to the survey researcher's categories. Interviewers are shown to act as mediators in difficult interaction, with responses often distorted by question format, the imperative of achieving an allowed response, and the need to keep the respondent in the survey. The analysis suggests that conversational resources could be used constructively to ensure a better fit between questions and responses.
\end{abstract}

\footnotetext{
${ }^{1}$ University of Tasmania. E-mail: Marian.May@utas.edu.au.
} 


\section{Introduction}

Where most households have telephones, population data are increasingly gathered through telephone surveys. In general, survey researchers work on the assumption that standardized surveys with fully scripted identical questions, delivered to each respondent exactly as worded by well-trained interviewers and probed in a neutral way, will on the whole obtain reliable and valid responses. At the same time survey methodologists acknowledge that full standardization is tricky and some suggest a more flexible approach to standardization (Maynard and Schaeffer 2002; Schober and Conrad 1997; Suchman and Jordan 1990).

Demographers, heavily reliant on survey data, have also been part of the 'larger movement' (Massey 1987:1516) of those advocating a more flexible approach. In the face of dissatisfaction with data quality and criticism of the efforts of the World Fertility Survey (WFS), and later the Demographic and Health Survey, to collect comparable data in a variety of settings (Caldwell 1985; Davis 1987; Stone and Campbell 1984; Ware 1977), some researchers incorporated a variety of adaptations and alternatives in their international fieldwork. These new approaches combined elements of both quantitative and qualitative research strategies (Axinn, Fricke, and Thornton 1991; Caldwell, Caldwell, and Caldwell 1987; Dyson and Moore 1983; Massey 1987). Demographers also incorporated the use of tape-recordings and transcripts (Adeokun 1981, Davis 1973, Gibril 1979, Pool and Pool 1971, Quandt 1973, all cited in Thompson, Nawab Ali, and Casterline 1982:8; Weinreb 2006). Yet, despite the importance of surveys in the collection of demographic data, investigations of the role of interaction in both quantitative and qualitative demographic data collection have been rare.

In the 1975-76 Bangladesh Fertility Survey report, Thompson et al. (1982:7) observed:

The interchange between the interviewer and the respondent is the keystone of the whole enterprise, yet evidence about this interchange ... is entirely indirect. Tape-recordings of the interviews offer a more direct view into the interviewing itself... with tape-recordings an opportunity is presented to consider in unusual detail and depth many aspects of interviewing.

and

The great value of the transcripts is the vivid picture they provide of the dynamics of the interview, including subtleties of social interaction not easily observed by any other means (Thompson et al. 1982:11). 
The focus on 'foreign' survey populations reflected the concern of researchers that translation of the survey instrument from English or French into the languages of respondents, an integral part of large-scale survey enterprises such as the WFS, might affect the reliability and validity of the data (Thompson et al. 1982:8). This concern does not seem to have been explicitly or convincingly expressed in relation to surveys where interviewers and respondents spoke the same language until Suchman and Jordan's (1990) analysis of five videotaped interviews and transcripts from the US General Social Survey and the National Health Interview Survey.

Since the early 1990s interest in interaction in surveys in general, and demographic surveys in particular, has been more evident. The development of tools for rigorous and systematic analysis of interaction in the field of ethnomethodology and conversation analysis (CA) has supported this interest (Sacks, Schegloff, and Jefferson 1974). Unlike earlier studies, however, interest mainly focuses on surveys where the interviewer and respondent ostensibly speak the same language (Schaeffer 1991; Schaeffer and Maynard 1996; Schaeffer, Maynard, and Cradock 1993; Schaeffer and Presser 2003; Schaeffer and Thompson 1992). This conversation-analytic approach sheds further light on the standardized interview as a source of social science data (Houtkoop-Steenstra 2000; Maynard et al. 2002; Suchman and Jordan 1990). The fact remains, however, that little research has examined interviewer-respondent interaction in any type of demographic data collection.

The research informing this paper examines interaction in the collection of demographic data where interviewer and respondent speak the same first language (May 2002). This paper examines how one interviewer, Annie, ${ }^{2}$ and 25 respondents from Australia's Negotiating the Life Course (NLC) survey achieved responses to the questions about birth timing in the Women on Children (WOC) survey. The WOC telephone survey re-asked 25 NLC respondents the 10 or so NLC questions about having children.

\section{WOC survey data}

To obtain the working sample of 27 respondents, women aged 20-54 years were randomly chosen, for reasons of accessibility, from the 400 Wave 1 NLC respondents of both sexes living in two areas only, New South Wales and the Australian Capital Territory. Two characteristics of the sample are worthy of particular note. First, none of the women was from a language background other than English; one woman, Jess, was an indigenous Australian, but English was her first language. Second, the WOC sample

\footnotetext{
${ }^{2}$ Interviewer and respondents have been given pseudonyms.
} 
contained a large number of older women-10 of the 27 were over 45 years of age at the time of the Wave 1 NLC survey in 1996-7. Most did not want to have more children. Chance appears to be the only explanation for this, as the WOC sample was drawn from the complete NLC female population. The WOC telephone interviews were conducted in December 1998 at the Australian Institute of Family Studies (AIFS), using one of the original interviewers from Wave 1 NLC.

Although, in terms of conventional survey methodology, using one interviewer maximises interviewer bias, it enables a focus on how different respondents interact with the same interviewer and the same questions on children, rather than introducing interviewer variability. The considerable research already conducted on interviewer behaviour suggests no strong reason to use more than one interviewer for such a small number of interviews. ${ }^{3}$ It might be concluded from interview excerpts that Annie was not a good interviewer, as she frequently broke the rules of standardised interviewing outlined in the AIFS manual for CATI (AIFS 1998). ${ }^{4}$ However, research on the conduct of survey interviews shows that, in practice, it is impossible for interviewers to behave as survey designers and trainers of interviewers might expect (e.g., Briggs 1986:Ch.3; Houtkoop-Steenstra 1995, 1996, 2000; Mazeland and ten Have 1998; Schaeffer et al. 1993; Suchman and Jordan 1990). This issue is followed up in analysis of interviews.

As a Wave 1 NLC interviewer, Annie was already familiar with the procedure used for the WOC survey. The WOC women also had already answered the WOC questions earlier when they participated in the Wave 1 NLC telephone interview. The concern that repeating the questions might affect their responses to the WOC questions was allayed by the fact that few women remembered being interviewed for Wave 1 NLC.

Interviews took place using a taping device linking the telephone to a cassette recorder. The interviewer coded responses immediately onto the questionnaires, according to the Wave 1 guidelines. I monitored calls from the supervisor's office in the way that a supervisor would routinely monitor interviews. This gave me a sense of immediacy that would not have been possible from replaying the tapes. Respondents were told that some of them would be selected for in-depth interview after the telephone interviews. Only three in-depth face-to-face interviews were conducted-with Annegret, Andrea and Dale. The questions used as a starting point for the face-to-face interviews were those in the previous telephone interview. Data obtained in the face-to-

\footnotetext{
${ }^{3}$ Cannell and Oksenberg 1988; Clark and Schober 1992; Dijkstra and van der Zouwen 1987; Fowler and Mangione 1990; Hagenaars and Heinen 1982; Houtkoop-Steenstra 1995, 1996, 1997a, 1997b; HoutkoopSteenstra and van den Bergh 2000; Schober and Conrad 1997; Sudman and Bradburn 1982; van der Zouwen, Dijkstra and Smit 1991.

${ }^{4}$ Annie was considered one of the most experienced, best trained and most competent NLC contract interviewers, meeting Frey and Oishi's (1995:110-17) role, ability and knowledge criteria for a good interviewer.
} 
face interview were compared with coded responses obtained from the earlier telephone interviews with particular focus on the understanding of responses to questions, the quality and type of responses, and the interactions and other factors which might influence the information that emerged.

Interviews were transcribed by the researcher, using the detailed conventions of CA (see Transcription Conventions following the text). Transcription using these conventions is time consuming, but provides a "powerful lens" (Moerman 1988:x) through which to view interaction. The CA concept of "trouble" in interaction is applied to the negotiation of responses to one NLC field-coded question on determinants of birth timing. Excerpts from the interviews show how interviewers and respondents interact to meet the demands of the survey researcher, breaking both the rules of survey interviewing and ordinary conversational interaction, and calling into question the validity of the research instrument.

\section{Survey interviews as interaction}

Telephone surveys involve three parties: the interviewer, the respondent and the researcher whose interests are reflected in the questions (Houtkoop-Steenstra 2000; Maynard et al. 2002). Interviewers mediate between researchers and respondents, matching questions and responses. Various aspects of questions can make them difficult for respondents to understand: grammar, word meaning, ambiguity, length and pragmatics (Tourangeau, Rips, and Rasinski 2000:Ch.2). Respondents can respond to questions in many different ways, and the "frame of reference" of respondent and researcher may differ (Kahn and Cannell 1957:113ff.). Survey researchers want to control the frame of reference of a question; that is, they want to be sure that the frame of reference of the question determines the personal frame of reference of the respondent. Researchers also aim to ensure that all respondents use the same frame of reference so that their responses are comparable. Techniques for controlling the frame of reference include learning the respondent's frame, indicating a specific frame, and selecting a common frame (Kahn and Cannell 1957:113ff).

The survey interview is a "complex interactive frame" (Houtkoop-Steenstra 2000:58-60) where a multiplicity of types of interaction can occur: interviewerrespondent, interviewer-questionnaire (representing the researcher), interviewercomputer monitor, and interviewer-keyboard. While in most cases the respondent interacts with the interviewer only, interactions for the interviewer are more complex, with computer hardware and software to manipulate and instructions from training sessions to remember. The questionnaire, predetermined and scripted by the researcher, is not a neutral force (Goody 1978; Houtkoop-Steenstra 2000); rather it is an active 
force in the interaction. Interviewer and respondent play a number of sometimes interchangeable roles in the interview: asking and answering questions, relaying information about question meaning, and keeping respondents in the survey, an important consideration in the WOC interviews.

The interviewer and respondent at times refer to the researcher as a third participant in the interviews. This occurs in the WOC interview with Jess where Annie distances herself from the question when problems arise:

\section{Excerpt 1 Jess}

199. Jess: $\quad m m$ it's couched in such- it's- it's very- i mean i hate- I

200.

201. Int: don't mean to be rude but the $\cdot$ hh [the w-

[MMPh\#9:199-201]

Frames of reference are explicated in the talk that occurs in survey interviews. At issue for researchers is whether respondents have responded to the question using the researcher's frame and how to interpret their responses.

For conversation analysts, the concept of "trouble" in interaction is fundamental. Where interaction proceeds without trouble, turns between speakers occur with no gap and no overlap (Sacks et al. 1974), and work does not need to be done by participants to repair problems. In troubled interaction, however, repair work is evident. Participants repair problems so that interaction can proceed; failure to do so can result in more serious breakdown. Analysing troubled interaction can provide clues to differences in frames of reference.

Even when interaction is untroubled or unproblematic, the frames of the interviewer and the respondent may still differ. Where the interaction is made transparent through detailed transcription, it often becomes clear whether the respondent has interpreted the question as the researcher intended. Without detailed transcription, researchers only have available to them the numerical outcome or achieved response option as the sole representation of the respondent's answer. Transcription of interaction reveals a great deal about the extent to which numerical responses are negotiated and agreed between the participants.

The following analysis categorizes interaction as follows: minimal and troublefree; extended but trouble-free; or extended and troubled. In theory, the most basic (shortest) sequence is a paired question-answer sequence, with the interviewer's 
question being answered directly by the respondent, with no gap. The number of turns taken to negotiate a response indicates whether an interaction is extended or minimal. Following Houtkoop-Steenstra (2000:109), the term "response" in this paper refers to the written interview schedule. Thus, a "response" matches predetermined response options or response categories provided on the interview schedule; "answer", on the other hand, refers to what respondents said in responding to the question in the verbal interaction. It may take considerable negotiation to move from an "answer" to a "response." The following example shows a minimal, trouble-free question-answer sequence:

\section{Excerpt 2 Annegret}

42. Int: a:nd are you currently pregnant?

43. Annegret: no.

[MMPh\#1:42-43]

Here the interviewer puts the question and the respondent answers with no trouble: no gap, no pause, no overlapping talk or interruption, and no hesitation or stumbling. This kind of basic untroubled sequence was rare in the WOC data. 


\section{NLC Question 167}

Q167 asks about the factors that determined the respondent's first birth (Fig. 1).

\section{Figure 1: Question 167, Negotiating the Life Course and Women on Children surveys}

(If Q154=0 and Q164=not 1): What will determine when or if you have your first child?

(If Q154=0 and Q164=1): What determined the timing of this pregnancy?

(If Q154=not 0): What determined the timing of your first child?

Prompt for two reasons (Any other reasons?)

\begin{tabular}{ll}
\hline I have to get a partner first & 01 \\
Convincing my partner that it's a good idea & 02 \\
It will happen when it happens & 03 \\
Unplanned, it just happened & 04 \\
Failure of contraception/family planning method & 05 \\
Wanted a child as soon as possible after marriage & 06 \\
Being established in my career & 07 \\
My partner being established in their career & 08 \\
Having enough money to buy a house & 09 \\
Feeling able to cope with the demands of a child & 10 \\
My relationship with my partner being well-established & 11 \\
After having time to enjoy myself before settling down & 12 \\
When I/we feel/felt right about it & 13 \\
Feeling financially secure & 14 \\
Other (specify) & 15 \\
\hline
\end{tabular}

[NLC 1997 Interview Schedule]

Q167 is a field-coded or semi-open question (Houtkoop-Steenstra 2000:4-5, 10727; Smit 1995:117). To respondents, a field-coded question appears to be an open question that they can answer in their own way. The question does not suggest a frame for the answer because response options are hidden from the respondent. The interviewer, on the other hand, has in front of her a list of allowable response options; thus, for the interviewer it is in effect a closed question, with "forced choice" responses 
(de Vaus 1995:86; Foddy 1993:135; Oppenheim 1966:44-45). The respondent's answer has to be formatted and coded by the interviewer into one of the allowed response options (Fowler and Mangione 1990:88). Thus, the field-coded design of Q167 adds a task for the interviewer: matching the response options provided by the researcher with the respondent's answer. This is more difficult when the respondent does not have the clues provided by the response options to guide her expectation of how she should answer.

Research confirms that using field-coded questions has pitfalls (Foddy 1993; Houtkoop-Steenstra 2000; Oppenheim 1966; Smit 1995; Smit et al. 1997; Sudman and Bradburn 1982). Fowler and Mangione (1990:88-89) and Oppenheim (1966:44-46) warn against using field-coded questions because they cause considerable bias and loss of information. Sudman and Bradburn (1982:294) suggest avoiding field-coded questions unless the verbatim response is also recorded so that field coding can be checked during processing. In the case of field-coded questions interviewers are very frequently required to take a mediating role (Houtkoop-Steenstra 2000:Ch.6; Smit 1995; Smit et al. 1997). Despite their pitfalls, field-coded questions are very common in surveys, perhaps particularly in telephone surveys where the list of response options is too long to be read to the respondent.

In theory the WOC interviewer should be able to obtain quick answers from respondents. The respondents have already answered the question in the NLC survey, and researchers established a frame for categorizing responses based on earlier fertility surveys (Australian Family Project 1986; Australian Family Survey 1971; Melbourne Survey Group 1979). This frame is reflected in the Q167 response options, available to the interviewer but not the respondent. The minimum interaction possible is four turns: the interviewer's question; the respondent's first response; the interviewer's probe; and the respondent's second response. However, the interaction was considerably longer than the minimum for most of the 25 respondents, taking between four and 22 turns to negotiate a response.

\section{Troubled interaction in the WOC interviews}

All 25 interviews showed some trouble in the interaction. The following transcripts of interaction on NLC Question 167 (Fig. 1) illustrate sources of trouble for all three parties to the interviews: difficulty with the field-coded question format; loss of detail and complexity from respondents' stories; ambiguity of concepts in the question; respondent acquiescence; directive probing; and arbitrary reframing of respondents' answers to fit the response options. This constellation of difficulties occurred in various combinations throughout the interview excerpts. 
The interaction with Nadia was the least troubled, taking the minimum number of four turns to complete the question. Even so, Nadia's interview shows what occurs when the respondent's answer does not use the words of an acceptable response option:

\section{Excerpt 3 Nadia $(04 ; 04)^{5}$}

81. Int: $\quad$ UUM (.) what determined the timing of your first child.

82. (2.0)

83. Nadia: accident.

84. Int: $\quad{ }^{\circ}$ accident. $^{\circ}(1.0)$ was it a failure of contraceptives?

85. (3.0)

86. Nadia: no. not really. just (carelessness) huh huh

[MMPh\#21:81-88]

Although the interaction is not extended, Annie cannot immediately decide on her response. Her choice of (04) Unplanned, it just happened seems reasonable. She probes directively, using response option (05) Failure of contraception, family planning method and receives a clear negative answer followed by laughter: "no. not really. just (carelessness) huh huh." Nadia's "accident." seems to make it redundant for Annie to probe for further reasons, as all other response options involve planning or premeditation of some kind and appear to be contradictory to the concept of "accident." Many respondents showed this pattern of responses, combining (04) with (05).

The first source of trouble for the interviewer was that no respondent's first answer exactly fitted any response option. In Nadia's case Annie was able to make the leap between what Nadia said and what was allowed as a response. However, of the 25 respondents, only one, Annegret, gave a first answer that used one of the topic words of an allowed response option- "career". Yet, the interaction required to allow Annie to circle two responses was considerably extended, partly because, in the absence of clear direction about what constituted an allowed response, Annegret's answer suggested several possible responses:

\footnotetext{
${ }^{5}$ Responses for both NLC Wave 1 and WOC are given in parentheses after the respondent's name for each excerpt, but interaction was recorded for the WOC survey. Thus, Nadia's response was the same for both surveys: (04) Unplanned, it just happened.
} 


\section{Excerpt 4 Annegret $(07,11 ; 02,07,13)$}

63. Int: and what determined the timing of your first child?

64. (2.3)

65. Annegret: u:::mhhh (2.0) i- hh my um (.) career had $>$ sort've<

66. reached a point where i felt (.) i could- (.) take a-

$67 . \quad$ (.) break, i guess,

68. Int: $\downarrow_{\text {sure, so you felt established. }}$

69. Annegret: a- an- and um (.) my husband was (.) finally ready.

70. huh huh huh huh [.hhh so, um yes $\left({ }^{\circ}\right.$ sort of $\left.{ }^{\circ}\right)$,

71. Int: [oi:: see::,

72. Int: (so let's just see) (0.6) hh there is one here which

73. says- i've got a whole list of (.) um possible (.) um

74. $\quad$ reasons, and one of them is ${ }^{\circ}$ convincing my partner it was

$75 . \quad$ a good idea(h) ${ }^{\circ}$

76. Annegret: \$yeah hh yeah that's one of them $\$$ huh huh huh

$77 . \quad$ [huh hhh

78. Int: [\$o(h)k(h)ay uhm i don't want to put words in your

$79 . \quad$ mouth, $\$$

80. Annegret: huh huh [.hhh hhh]

81. Int: [ oka:y ] and was it also that your

82. relationship was established and (.) you felt like

83. (.) $)^{\mathrm{o}}$ it was (.)it was time ${ }^{\mathrm{o}}$ to (just),

84. Annegret: $\uparrow$ um $\cdot$ hhhh (1.0) o::h no:: >i mean we- we've had a

$85 . \quad$ (.) very long relationship, so i don't think that

86. sort of really came into [it=

87. Int: [right.

88. Annegret: =it was just a matter of (.) that we were both ready.

89. Int: $\cdot$ hhh

90. (4.0)

91. Int: a::nd how many children ((next question))

[MMPh\#1:63-91] 
Annie formulates Annegret's answer using the words of response option (07): "sure, so you felt established." Annegret signals tacit agreement by moving on with no pause to provide a second reason: "a- an- and um (.) my husband was (.) finally ready. huh huh huh huh hhh so, um yes (sort of)," The mention of her husband allows Annie to link Annegret's answer with response option (02) Convincing my partner that it's a good idea. Annie then acknowledges that she has a list of response options and mentions this option. Annegret laughingly agrees. Annie checks again and makes the point explicitly that she does not want to put words into Annegret's mouth. Using the words of a response option as a probe proves a successful strategy for Annie in this interview; it results in a speedy outcome by providing an alternative to the respondent's own words. The question takes a lengthy fourteen turns to complete, mainly because Annie confirms (07) as a response (line 81ff.). On the interview schedule Annie circled three response options: (02) Convincing my partner that it's a good idea, (07) Being established in my career, and (13) When I/we feel/felt right about it.

In NLC Wave 1 the two response options recorded for Annegret were (07) Being established in my career and (11) My relationship with my partner being well established. Annie rejects response option (11) here (lines 84-86). Her answer in line 88 appears to be translated into response option (13) When I/we feel/felt right about it. This is not confirmed or rejected by Annegret but is entered by Annie as a response on the interview schedule.

Annegret was one of three respondents interviewed in depth face-to-face following her telephone interview. When asked about the questions, ${ }^{7}$ Annegret said, "the way the questions were posed were really leading questions in many ways anyway so then you ask a question that it's very hard to pick the answer and then you have to prompt the answers and then you know...." Her own telling of the decision to have a child was quite different (Excerpt 5). ${ }^{8}$

\footnotetext{
${ }^{6}$ Annie's obvious infringement throughout the interview of the rules of standardised interviewing, as outlined in her training manual (AIFS 1998), reflects common interviewer behaviour (Briggs 1986:Ch.3; HoutkoopSteenstra 1995, 1996, 2000; Mazeland and ten Have 1998; Schaeffer et al. 1993; Smit et al. 1997; Suchman and Jordan 1990).

${ }^{7}$ In-depth interviews were "roughly" transcribed for triangulation purposes in this research; that is, CA symbols were not used, but transcription is of the detail that would normally be included in qualitative research (Briggs 1986). The focus is not on interaction, though it is just as important in in-depth interviews (Briggs 1986; Cicourel 1974; Mazeland and ten Have 1998); the purpose here is to compare what the respondent says on two occasions.

${ }^{8}$ The full in-depth interview with Annegret is available on request to the author.
} 


\section{Excerpt 5: Annegret}

Annegret: $\quad$ yeah well we- we- i mean- we'd been married for a long time and uhm i mean- we'd always intended to have children it was like just a question of sort of being ready to have children uhm and we sort of said oh yeah but one day you know

Marian: yeah

Annegret: anyway eventually we agreed that it was about the right time and uhm i'd been off the pill about six months and so then practically the first thing I actually got pregnant so it was it was sort of uhm it was just a good time in in my career to uhm take the time and Brian was- knew it'd be a lot of hard work and we were realistic about that but but like we'd been saying afterwards we wanted to be sure that it was such a big step to the extent that she was born in the mid-semester break so that he could take time off

Marian:((laughing)) that's good timing

Annegret: we're just lucky we got pregnant ... yeah so that was just really lucky you know we were able to get pregnant and take time off to have lectures and stuff to be at home for a week it's funny i mean probably the second time I know I think he would just basically say oh it doesn't matter when it happens I'll do it anyway but uhm the first time although you know it's gonna be- like I want to work but you still don't know until it actually happens without thinking about what that means in terms of parenthood and all of that- all the emotional thing that goes with it yeah so

[MMID\#1]

In all other WOC interviews Annie had to interpret the respondent's "unformatted" first answer in order to format it in terms of a response option. In some cases this seemed, on the surface, a reasonable interpretation: Nadia's and Karen's "accident," Coral's "bad luck," Ricky's "stupidity...mistake...bad news," and Jess and Sonya's "fate" first answers were recorded as (04) Unplanned, it just happened. Had the question format been different, with respondents presented with an explicit set of response options, this issue of reformatting answers may have been avoided. Examining the interaction, however, suggests that this reformatting might sometimes be an oversimplification, leading to a loss or distortion of information. Thus, a second source of trouble, this time affecting the data, is a loss of detail and complexity from respondents' stories.

Karen's interview (Excerpt 6) demonstrates another combination of problems: how detail and complexity can be lost from the respondent's story; the ambiguity of the terms 'planned' and 'unplanned', as used in the response options; and interviewer use of directive probing to resolve the response. 


\section{Excerpt 6 Karen $(04 ; 04,11,13)$}

78. Int: $\quad \mathrm{a}::: \mathrm{h}$ what

79. determined the timing of your first child.

80. Karen: accident.

81. Int: accident.

82. Karen: ah hah hah hah [hah

83. Int:

[was it actuall(h)y- hh was it a failure?

84. of contraception? or family planning method? or just

$85 . \quad$ unplanned.

86. Karen: just unplanned actually $i$ we'd been- we'd been- married

87. for five years, and we thought we'd try, and then we

88. tried and (.) nothing much happened so i started

89. $\quad$ studying and (.) blow me down my second study packages

90. arrived and i find i'm pregnant. [ah hah hah hah hah

91. Int:

$$
\text { [o::::h. }
$$

92. Int: so you'd actually got to the point where you

93. felt right about it=>(sort of/things) you know $<$ like-

94. you were established in your relationship and

95. [( )

96. Karen: [yeah. o::h definitely. [definitely.

97. Int:

[yeah? well we'll put that down

98.

too then. (0.6) u:m (1.3) t! (1.0) yep (.) $\uparrow \mathrm{hh}$ and $\uparrow \mathrm{a}: \mathrm{h}$

[MMPh\#19:78-98]

Karen's "accident" is eventually reframed and recorded as (04) Unplanned, it just happened, the only response option circled for this question. Annie probes, giving Karen a choice of three options, the first two of which did not apply: "was it actuall(h)y- hh was it a failure? of contraception? or family planning method? or just unplanned." (lines 83-85). The word "unplanned" is used first by Annie and then confirmed by Karen. Karen's answer implies that the timing was unplanned but having a child was planned. Because it is asked as a yes-no question, this probe is directive and suggestive to the respondent of how she should answer. For Annie it is a pragmatic 
solution to her difficulty of obtaining a response option that fits the frame of the question.

Karen's explanation suggests far more detail and complexity than can possibly be captured by response option (04). Annie puts up a candidate answer (lines 92-95): "so you'd actually got to the point where you felt right about it $=>$ (sort of/things) you know< like- you were established in your relationship and ( )." This answer is formulated in terms of two response options, (11) and (13), and presented together as one yes-no question. Again, Annie has infringed the interviewer's rule of probing only in a neutral way. This seems to have led to her circling options (11) My relationship with my partner being well established and (13) When I/we feel/felt right about it. Both these options give the impression that this was what "determined" timing; neither comes spontaneously from Karen, though she signals definite agreement.

The interaction here raises the question of what constitutes "planning" when it comes to the timing of a birth. Is it "unplanned" when Karen becomes pregnant at this stage, having wanted to become pregnant in the past? The ambiguity of the phrase "timing of your first child" means that sometimes the question could be interpreted as referring to the timing of the conception of the child and sometimes to the timing of "having" a child or continuing the pregnancy. It is hard to see what conclusions could be drawn from these responses without the benefit of further explanation.

Annie also recorded (04) Unplanned, it just happened for the interview with Jess (Excerpt 7), mother of a young baby. The interaction shows how the interviewer uses directive probing and formulation, using the words of response options in a candidate answer: 


\section{Excerpt 7 Jess $(01,14 ; 04)$}

63. Int: $\quad \mathrm{u}::: \mathrm{m}($.$) what determined the timing of your first child.$

64. (0.6)

65. Jess:

.h fate. ahHAH HAH HAH nHAH HUH HUH HUH $\cdot$ hh hold on a

66. moment until we see if he's quiet or see if he

67. squeals $=$ no=totally unexpected.

68. Int: and was it actually a failure of contraception or family

69. planning method?

70. (1.0)

71. Jess: o:::hhh let's see::, let's see: ubwa wa wa wa (.).hh i

72. guess yeahi hhh[hh ](h)

73. Int:

74. Jess:

75. Int: well actually no:: no:[: ] not- no:: not at all. just-=

76. Int: [no.]

77. Jess:

$=$ it was just unplanned

78. Int: ${ }^{\circ}$ ye:ss. it was unplanned. ${ }^{\circ}$

79. Jess: $\left(^{\circ}\right.$

80. Int: MM HM yars $\mathrm{a}:: \mathrm{h} \uparrow$ no::w $\uparrow_{\text {how }}$ many children ((next question))

[MMPh\#9:63-80]

Annie records only one response for Jess-(04) Unplanned, it just happened. She attempts to obtain a second by using a yes-no question, a directive probe based on (05) Failure of contraception/family planning method. Jess signals that this question is difficult for her, with lengthened syllables, discourse markers, repetition and pauses, ending with rising intonation. When prompted by Annie's "yes?" she changes her mind: "well actually no:: no:: not- no:: not at all. just-," again showing features of a troubled response. Annie finishes her sentence for her, providing her with a candidate answer: "it was just unplanned." Jess confirms this: "ye:ss. it was unplanned." and Annie moves on to the next question without prompting for a second reason. Annie makes a decision based on Jess's responses to her directive probes without knowing the situation Jess is recalling; Jess is answering Annie's questions without knowing that only some answers are acceptable as responses. 
Formatting first answers of other respondents took more effort. First answers mentioned concepts as disparate as "miracle," "seven-year itch," "carelessness," "young and silly," and "don"t know." Merilyn said, "nothing really," and Joanne mentioned "desire." Carol's first answer was the beginning of a story: "hh o::h hh um now, let's see. 'hh >what was that< well. um. (0.6) 'hh we'd been married fo::r hh thh hh well we'd been together f- 'hh now ha- >how long- nineteen eighty three she was born and < -hh so we'd been together for about five yea:::rs, we came back to Australia, 'hh we (.) bought a hou:se, so- it- we sort of seemed fairly settled, 'hh."

The first answers of Andrea, Melinda, Lyn, Edith, Jenny, Noelle, and Kristen all resulted in much more work for the interviewer and respondent to negotiate the response options. Andrea gave "age" as an answer, an option rather surprisingly not included in the list, given the relationship between age and women's reproductive cycle, and an option not easily interpretable in terms of any other option. Noelle and Kristen persisted in telling their own reasons in their own way and produced no reason that matched the frame of the researcher in the available response options. Kristen gave being on fertility drugs as an answer; Noelle answered in terms of wanting a child. Neither of the responses eventually recorded for Noelle was initiated by Noelle, and after 18 turns no response was recorded for Kristen.

For Edith (Excerpt 8) the wording of the question was troublesome. The excerpt illustrates once again the use of directive probing and candidate answers, driven by the interviewer's need for a response: 
Excerpt 8 Edith $(05 ; 04,05,13)$

124. Int: $\quad$ okay. ${ }^{\circ} \uparrow$ now $\uparrow$ what detim- what determined (.) the timing of your first child.

126. Edith: a::h (1.3) what determined?

127. Int: $\mathrm{mm}$. what- was it- you know- you- you were just newly married and wanted to have a child as soon as possible

129. ( )

130. Edith: no no not at all.

131. Int: $\left({ }^{\circ}\right.$ it was unplanned ${ }^{\circ}$ )

132. Edith: 个yea:h. it was. $=[i$ was on the pill.

133. Int: [hah hah

134. Int: oh. ri::ght.

135. Edith: $\quad$ yeah. (1.0) and the second one i had an IUD.

136. Int: oh. right.

137. Edith: ${ }^{\circ}$ yeah $^{\text {oo }}$

138. Int: AND AH- SO (.) but obviously you were (.) in a relationship where (you would [have ] received a lot=

140. Edith: ['oeah.]

141. Int: $=$ of support.)

142. Edith: $\quad$ yeah. yeah. $^{\circ}$

143. (1.3)

144. Int: 个ñw a::h- i’m going to read you ((next question))

[MMPh\#17:124-44]

When Edith queries "what determined?" (line 126), Annie abandons the scripted question in favour of a yes-no question based on a response option. Two other respondents, Kristen and Noelle, asked for repetition of the question. It seems that the concept of determining timing caused them some difficulty; in addition, the wording is rather more formal than the language likely to be used by most women in daily conversation. "Determine" is a word favoured by social scientists in their quest for ascertaining cause and effect; in daily conversation women would be less likely to use such a formal term and more likely to ask something like: "Why did you have your first 
baby when you did?" or "What made you have children when you did?" Here, Annie takes on a mediating role, translating the more academic term into an example using one of the response options.

Annie's yes-no question, formatted in terms of response option (06) Wanted a child as soon as possible after marriage, again breaches rules for interviewer behavior. ${ }^{9}$ When this is rejected, Annie puts up an apparently arbitrary candidate answer based on response option (04): "(it was unplanned)." Her laughter when this was emphatically accepted by Edith was a laugh of surprise, perhaps because she had guessed correctly. Edith equates "unplanned" with "failure of contraception" here. Later (line 138) Annie's use of "obviously" and her directive probing statement make it very difficult for Edith to decline Annie's formulation of her situation. ${ }^{10}$ Annie circles option (13) When I/we feel/felt right about it for this interview, when there appears to be no evidence for this in what Edith says; in fact, (11) My relationship with my partner being well established might have been a closer interpretation, based on the participants' interaction.

WOC respondents, like Edith, often appear to be going along with what the interviewer is saying as a response to a formulation. To say "no" to a formulation, a respondent must do more interactional work, particularly when her decision is to reject the interviewer's formulation. It is much harder to disagree than to agree with a formulation. This is particularly so if the formulation is partially accurate. However, without knowing the response options, the respondent is not in a position to agree to the "best fit" among all response options. Here, Edith seems to assent to Annie's understanding. Houtkoop-Steenstra (2000:121-27) gives many examples of respondent acquiescence, noting: "The standardized survey interview is typically a social interaction in which the respondents readily agree with the interviewers' statements, even though they may not be (quite) correct." Molenaar and Smit (1996) show that respondents usually give agreeing answers to "one-sided positive yes-no questions." Houtkoop-Steenstra (1997b:3,5) notes that the use of low-volume talk in research interviews is associated with passivity: "Conversationalists use low volume to indicate that they are not ready to take the turn, or to indicate their preparedness to give up the turn." Does yeah (particularly a soft yeah) always mean "yes"?

A respondent puts an interaction in jeopardy by "disconfirming" an interviewer's formulation, hence putting the sense of the interaction so far back to "square one" (Heritage and Watson 1979:136-53). Molenaar and Smit (1996:133-34) found that, since "both the interviewer and the respondent care about their relationship," some

\footnotetext{
${ }^{9}$ See, for example, Suchman and Jordan (1990:233ff). Houtkoop-Steenstra (1997a:613) and HoutkoopSteenstra and Antaki (1997:285-313) note that this is frequent interviewer behaviour.

${ }^{10}$ Houtkoop-Steenstra and Antaki (1997:299) found that declarative questions such as this have the same effect as leading or directive questions. They are used when speakers have good reason to believe the proposition to be a fact; that is, when they already believe that they have the answer.
} 
contributions may reflect "an act of politeness rather than a sincere opinion." Houtkoop-Steenstra (1996:216-19) notes, on the basis of Dutch interviews, that "yes" (ja) often may not mean "yes" but, rather, be acquiescence in the face of difficulties in addressing the frame of the question.

The longest and most complex interaction for Q167 occurs in the interview with Dale (Excerpt 9). This interaction brings together many of the features illustrated in earlier excerpts: the need to reformat the respondent's first answer; extensive use of directive probing, together with the formulation of candidate answers, arbitrarily using the words of response options as a means of resolving the difficulties of obtaining a response.

\section{Excerpt 9 Dale $(10,08 ; 10,13,14)$}

77. Int: $\quad{ }^{\circ}$ oka: $y^{\circ}$ so what $\uparrow$ will determine when or if you have um $t$ ! (0.6)

78. $\quad{ }^{\circ}$ a child ${ }^{\circ}>$ oh hold on no $<$ [what determined the timing of your $=$

79. Dale: [no

80. Int: $=$ first child $={ }^{\circ}$ that's the first question ${ }^{\circ}$

81. Dale: $\quad$ u $::: m(1.3)$ o:h. (1.0) probly:: age factor i'd sayi

82. Int: your- your age? [(you mean)] so u:m (.) was that $\mathrm{a}: \mathrm{h}=$

83. Dale: [yeah yeah ]

84. Int: =that you felt (.) that you were getting (.) to the point at

85. which you wanted to make a decision before you got too old?

86. Dale: yes. you know, like i didn't want to be too old to enjoy her

87. hah hah hah

88. Int: yeah.

89. Dale: $\uparrow_{\text {yeah. }}$

90. Int: ( $\left.\quad{ }^{\circ 0}{ }^{\circ}\right)(($ baby noises $))$ and (.)

91. were there also considerations about $\mathrm{u}: \mathrm{m}$ wanting a child as

92. soon as possible after you were married? ( )

93. Dale: $\quad \uparrow a:: \mathrm{h} \uparrow$ oh $\uparrow$ no not really, we <sort of $>$ (.) u:m (1.3) oh i guess

94. probly a few friends (.) 'n family and that started having

95. them, and we thought oh we: $\mathrm{h}$ we liked being around them so

96. maybe it's about time we(h)e(h): [(.) $\cdot$ hh] thought about= 
97. Int:

[right ]

98. Dale: =having one of our own $i$

99. Int:

${ }^{\circ}$ okay $^{\circ}$ so felt able to (.) cope with the demands of a chi[ld?

100. Dale:

[yeah.

101.

102. Int:

103. Dale:

104. Int:

105.

106. Dale:

107.

108.

109.

yes i think so,

110. Int: and also:: u:m felt right about it=[that- ] these are just=

111. Dale:

$=$ different options that $\left(^{\circ}\right.$ [mm hm]

(u:m) $\uparrow$ were finances a consideration at all? (

$\left.{ }^{\circ}\right)$

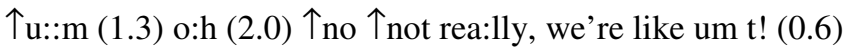
well (.) i mean i'm- i'm on- (.) on maternity leave for twelve mo:nths, so we had to sort of make sure that we could afford tha:ti $\mathrm{u}:: \mathrm{m}$

before you deci[ded.

112. Int:

[before we decided; so

113. Dale:

114. so financial security was [(a consideration)

[yeah i'd say financial security

[MMPh\#8:77-114]

Annie circled three response options as a result of this interaction: (10) Feeling able to cope with the demands of a child, (13) When I/we feel/felt right about it, and (14) Feeling financially secure. Underneath the response options she wrote: "age was a factor didn't want to be too old. Friends had kids \& we liked hanging around them so we decided to have one too."

Annie's first task is to ascertain which variant of the question to ask. Dale's "no" (line 79) mirrors Annie's and seems to indicate that Dale, too, hears this as an inappropriate question for her. She thinks for some time before coming out with her answer: "u:::m (1.3) o:h. (1.0) probly:: age factor i'd say." This answer is not one of the responses that Annie has before her. ${ }^{11}$ She reformulates Dale's answer but in different terms again from any of the response options. Thus, she is no closer to a response after

\footnotetext{
${ }^{11}$ The fact that "age" comes up quite frequently as a first answer suggests that it could usefully be included in the list of response options. However, its appearance as a first answer may not be transparent to the survey designer if the interviewer then goes on to record two allowable responses.
} 
two attempts, but her reformulation is met with approval from Dale, followed by laughter: "yes. you know, like i didn't want to be too old to enjoy her hah hah hah."

No material from Dale's previous response on age suggests a logical next topic or likely question to elicit an allowed response option (lines 86-87). Annie asks a yes-no question framed in terms of response option (06), providing Dale with a candidate answer: "and (.) were there also considerations about u:m wanting a child as soon as possible after you were married?" (line 90). In doing so she converts the response option material into a yes-no question that can be asked as a seemingly natural part of the conversation, rather than sounding like one of a list of possible responses in front of her. ${ }^{12}$ Annie's choice of (06) as the first candidate answer from the list of options seems arbitrary. If Annie were looking for a new topic to provide a second reason, having not succeeded with "age" as a reason allowed on the questionnaire, she could have asked about any of a number of others on the list: (02), (07)-(09), or (11)-(14). If she were working systematically down the list, she might have been expected to ask about response option (02) in this way; she behaves differently with other respondents. The WOC interviewer is given wording for prompting for a second reason (Any other reason?), and in a standardized survey interview it might be expected that she would use this wording. However, Annie's arbitrary use of specific response options reframed as yes-no questions is noted in previous research as being a very common strategy for interviewers faced with field-coded questions (Houtkoop-Steenstra 2000:Ch.6; Smit 1995; Smit et al. 1997).

In any case, Dale rejects Annie's candidate answer as a possible reason (line 93). She then gives her own reason: "we sort of (.) u:m (1.3) oh i guess probly a few friends (.) 'n family and that started having them, and we thought oh we: $\mathrm{h}$ we liked being around them so maybe it's about time we(h)e(h): (.) hh thought about having one of our own." Annie uses a formulation here, phrased as a yes-no question in the words of response option (10): "okay so felt able to (.) cope with the demands of a child?" The omission of "you", which would be expected to be included in addressing someone in conversational interaction, underlines that this comes from the response option. Dale's answer "yeah. yes I think so," is not convincing agreement; the final rising intonation leaves it unfinished. Annie moves on without a pause to give another formulation candidate answer using words from response option (13) (line 102). This time she openly acknowledges the options for the responses, but the use of "just" minimizes what follows (Schiffrin 1987).

\footnotetext{
${ }^{12}$ Heritage and Watson (1979:152), Houtkoop-Steenstra (2000:Ch.4), and Molenaar and Smit (1996) note this phenomenon. Interviewers often abandon the rules of standardized survey interviewing and follow the principles of ordinary conversation to manage the interaction. Respondents sometimes become confused when interviewers adhere strictly to standardized interviewing procedures, appearing to be incompetent conversationalists (Houtkoop-Steenstra 2000:69-85).
} 
Dale responds to Annie's statement (no longer a question)(line 103) with an acknowledgement token, "mm hm." Annie seems to have taken this as agreement, as she circled (13) on the questionnaire. Even though she already seems to have two reasons, she asks another yes-no question, this time using "finances" as a topic, also the topic of response option (14). Annie asks this question in a casual, conversational manner (Molenaar and Smit 1996). Dale replies that finances were not really a consideration, but comes around to agreeing that financial security was a consideration (line 113): "yeah i'd say financial security yeah." This agreement is convincing because "yeah" is repeated with falling (final) intonation. What prompted Dale to see "finances" and "financial security" as different is not evident without further explanation. Had Annie not reformulated the question from "finances" to "financial security", she might not have circled (14) Feeling financially secure as a response option.

It is unclear what would have happened had Annie asked instead about another of the response options not already covered, such as (02), (07), (09), (11), or (12). Maybe one of these options would have been circled instead. Again, the transcript suggests that the process of confirming that particular response option was a result of the interactional processes occurring between Annie and Dale rather than a direct response to the question. This may go some way to explaining the response option (08) My partner being established in their career recorded for Dale's second response in the NLC Wave 1 interview. A different interviewer may also have probed differently; responses may have been obtained in a different order and primacy assigned differently.

Throughout this interaction Annie is clearly suggestive in her approach to probing and putting up candidate answers. Left to her own devices, would Dale have come up with the same reasons and would she have circled the same response options? Would she have used the same words as the response options to describe her experience? If Dale told her experience in her own words and her own way, it may be that none of the options recorded for the two survey interviews would figure in her story. In her in-depth interview, for example, Dale talked at length about the role of her partner's and her family's support in her decision to have a child, a factor that was not clearly represented among the response options for the question.

\section{Conclusion}

The WOC telephone-interview excerpts illustrate some of the ways in which one interviewer acts as a mediator between the designers of a survey question and individual respondents in negotiating responses to a question. The interviewer plays a vital role in interpreting the question to the respondent and interpreting the respondent's answer in terms of the response codes provided by the researcher. Turn-by-turn analysis 
of interviewer-respondent interaction is shown to provide a rich source of feedback for the researcher and interviewer: whether questions work as intended, whether response categories are useful, how bias occurs, how respondents might interpret the question, and what kinds of factors make interactions longer, more complex and, thus, more costly.

In all 25 WOC interviews the process of negotiating a response was complex, and in most the interaction was extended. The difficulty of the question wording was further complicated by the field-coded format. The analysis of interview transcripts confirms previous studies, showing that, faced with field-coded questions, interviewers have little alternative but to engage in non-standard and directive behavior to achieve a response that matches an available response option. This behavior includes the use of formulation, yes-no questions phrased in terms of response options, arbitrary selection of particular response options as candidate answers, and apparently arbitrary interpretation of the respondents' answers in terms of the allowable response options for this question. These findings provide further evidence against using the field-coded question format.

A further problem raised by examination of these transcripts is that the responses recorded by the interviewer often distort the respondents' explanations of the timing of their first child. This sets up a tension between the interviewer's purpose of obtaining an allowable response and the respondent's purpose of explaining her behaviour as accurately as she can, on the assumption that the researcher wants to know what really happened in her case. The detail of the stories, then, is often manipulated, in fact unintentionally censored, in the interests of obtaining a response. Those "difficult" respondents who persist in holding to their story are sometimes excluded from the analysis because they insist on accuracy or resist the interviewer's attempts to put them into a category they see as inappropriate. Even though the participants in this research were all first-language English speakers, the complexities of the translation and interpretation task are evident: analysis of interaction data shows that a mismatch frequently occurred between what the researcher intended by the question and the way in which the interviewer and respondents interpreted it.

The implications for second language surveys, therefore, are considerable. Factors that influence interaction in an Australian English setting may be very different from those operating in other cultural and linguistic settings; cross-cultural and crosslinguistic interaction is likely to be even more complex. The findings have implications for surveys such as the WFS, the Demographic and Health Surveys, and the International Social Survey. Closer examination of interaction on the questions used might provide some insights into the data problems reported with these surveys. The transcribed excerpts show that validity is at stake. Responses are negotiated locally, turn by turn, by interviewer and respondent, making use of everyday conversational 
practices to maintain a social relationship that enables the interviews to be completed without serious breakdown. If interviewers and respondents did not adhere to these social conventions, the possibility of breakdown in interaction would be increased, thus endangering respondents' participation in future waves of the survey. The excerpts above show just how impossible a demand standardization is, particularly when complicated by the field-coded question format. If respondents' frames for their behaviour are important to survey researchers, survey work needs to be supplemented with qualitative methods, such as CA, that reveal these frames. Conversational resources available to interviewers could then be utilized in a positive and constructive manner to ensure that respondents understand questions in the way that researchers intend and that their responses fit the questions.

\section{Acknowledgements}

Thanks are due first and foremost to the women who were willing to have their stories heard, and to reviewers for their valuable and encouraging comments. My colleagues in the Demography and Sociology Program, Research School of Social Sciences, The Australian National University gave invaluable support to the research. I would like to express my particular appreciation for the insight and contributions of the late Dr. Thomas Schindlmayr. 


\section{References}

Adeokun, L.A. (1981). "The Next Child: Spacing Strategy in Yorubaland (with translations from taped interviews)." African Demography Working Paper No.8. Philadelphia: Population Studies Research Center, University of Pennsylvania.

Australian Family Project (1986). Men's Responses to Open-ended Questions: Question 61, Respondents 0001-2182. Canberra: Department of Demography, The Australian National University.

Australian Family Survey (1971). Vol. 9: Survey Papers. Canberra: Department of Demography, The Australian National University.

Australian Institute of Family Studies (1998). Computer Assisted Telephone Interviewing: Interviewer Manual. Melbourne.

Axinn, W.G., Fricke, T.E., and Thornton, A. (1991). The Microdemographic Community-Study Approach: Improving Survey Data by Integrating the Ethnographic Method. Sociological Methods and Research 20 (2):187-217.

Briggs, C.L. (1986). Learning How to Ask: A Sociolinguistic Appraisal of the Role of the Interview in Social Science Research. Cambridge: Cambridge University Press.

Caldwell, J.C. (1985). Strengths and Limitations of the Survey Approach for Measuring and Understanding Fertility Change: Alternative Possibilities. In: J. Cleland and J. Hobcraft (eds.) Reproductive Change in Developing Countries: Insights from the World Fertility Survey. London: Oxford University Press, pp. 45-63.

Caldwell, J.C., P. Caldwell and B. Caldwell (1987). Anthropology and Demography: The Mutual Reinforcement of Speculation and Research. Current Anthropology 28 (1): $25-43$.

Cannell, C. and L. Oksenberg (1988). Observation of behavior in telephone interviews. In R.M. Groves, P.P. Biemer, L.E. Lyberg, J.T. Massey, W.L. Nicholls and J. Waksberg (eds.) Telephone Survey Methodology. New York: John Wiley and Sons, pp. 475-95.

Cicourel, A.V. (1974). Theory and Method in a Study of Argentine Fertility. New York: John Wiley and Sons. 
Clark, H.H. and M.F. Schober (1992). Asking questions and influencing answers. In J.M. Tanur (ed.) Questions about Questions. New York: Russell Sage Foundation, pp. 15-45.

Davis, D. (1973). Event Recall and Temporal Judgment in the Moroccan National Census. Unpublished chapter from doctoral dissertation. Department of Psychology, University of Michigan.

Davis, K. (1987). The World's Most Expensive Survey. Sociological Forum 2 (4): 829-34.

de Vaus, D.A. (1995). Surveys in Social Research. Fourth edn. Sydney: Allen and Unwin.

Dijkstra, W. and J. van der Zouwen (1987). Styles of interviewing and the social context of the survey-interview. In H.-J. Hippler, N. Schwarz and S. Sudman (eds.) Social Information Processing and Survey Methodology. New York: Springer-Verlag, pp. 200-11.

Dyson, T. and M. Moore (1983). On Kinship Structure, Female Autonomy, and Demographic Behaviour in India. Population and Development Review 9, 1:3560 .

Foddy, W. (1993). Constructing Questions for Interviews and Questionnaires: Theory and Practice in Social Research. Cambridge: Cambridge University Press.

Fowler, F.J. and T.W. Mangione (1990). Standardized Survey Interviewing: Minimizing Interviewer-related Error. Newbury Park, CA: Sage.

Frey, J.H. and S.M. Oishi (1995). How to Conduct Interviews by Telephone and in Person. Thousand Oaks, CA: Sage.

Gardner, R. (1994). Conversation Analysis Transcription. Australian Review of Applied Linguistics Series $S$ 11: 185-91.

Gibril, M.A. (1979). Evaluating Census Response Errors: A Case Study for the Gambia. Paris: OECD.

Goody, E.N. (ed.) (1978). Questions and Politeness: Strategies in Social Interaction. Cambridge: Cambridge University Press.

Hagenaars, J.A. and T.G. Heinen (1982). Effects of role-independent interviewer characteristics on responses. In W. Dijkstra and J. van der Zouwen (eds.) Response Behaviour in the Survey-Interview. London: Academic Press, pp. 91130. 
Heritage, J.C. and D.R. Watson (1979). Formulations As Conversational Objects. In: G. Psathas (ed.) Everyday Language: Studies in Ethnomethodology. New York, Irvington, pp. 123-63.

Houtkoop-Steenstra, H. (1995). Meeting Both Ends: Between Standardization and Recipient Design in Telephone Survey Interviews. In: P. ten Have, G. Psathas (eds.) Situated Order: Studies in the Social Organization of Talk and Embodied Activities. Washington, DC: International Institute for Ethnomethodology and Conversation Analysis, and University Press of America, pp. 91-106.

Houtkoop-Steenstra, H. (1996). Probing Behaviour of Interviewers in the Standardised Semi-open Research Interview. Quality and Quantity 30: 205-30.

Houtkoop-Steenstra, H. (1997a). Being Friendly in Survey Interviews. Journal of Pragmatics 28: 591-623.

Houtkoop-Steenstra, H. (1997b). The Interactional Function of Soft Talk in Research Interviews. Paper presented at Fifth Cognitive Linguistics Conference, 14-19 July, Amsterdam.

Houtkoop-Steenstra, H. (2000). Interaction and the Standardized Survey Interview: The Living Questionnaire. Cambridge: Cambridge University Press.

Houtkoop-Steenstra, H. and C. Antaki (1997). Creating Happy People by Asking Yesno Questions. Research on Language and Social Interaction 30 (4): 285-313.

Houtkoop-Steenstra, H. and H. van den Bergh (2000). Effects of introductions in largescale telephone survey interviews. Sociological Methods and Research 28 (3): 281-300.

Jefferson, G. (1984). Notes on a Systematic Deployment of the Acknowledgement Tokens 'Yeah' and 'Mm hm'. Papers in Linguistics 17: 197-206.

Kahn, R.L. and C.F. Cannell (1957). The Dynamics of Interviewing: Theory, Technique, and Cases. New York: John Wiley and Sons.

Massey, D.S. (1987). The Ethnosurvey in Theory and Practice. International Migration Review 21 (4): 1498-1522.

May, M.B. (2002). Asking Women about Having Children: Interaction in TelephoneSurvey Interviews. PhD thesis. Canberra: Demography and Sociology Program, Research School of Social Sciences, The Australian National University. 
Maynard, D., H. Houtkoop-Steenstra, N.C. Schaeffer and J. van der Zouwen (eds.) (2002). Standardization and Tacit Knowledge: Interaction and Practice in the Survey Interview. New York: John Wiley and Sons.

Maynard, D. and N.C. Schaeffer (2002). Standardization and its discontents. In D. Maynard, H. Houtkoop-Steenstra, N.C. Schaeffer, J. van der Zouwen (eds.) Standardization and Tacit Knowledge: Interaction and Practice in the Survey Interview. New York: John Wiley and Sons, pp. 3-45

Mazeland, H. and P. ten Have (1998). Essential Tensions in (Semi-)Open Research Interviews. <http://www.pscw.uva.nl/emca/ET.htm>. Accessed 21 October, 1998

Melbourne Survey Group (1979). Melbourne Survey 1977: Vol. 2 Recently Married 516 Females. Canberra: Department of Demography, Australian National University.

Moerman, M. (1988). Talking Culture: Ethnography and Conversation Analysis. Philadelphia: University of Pennsylvania Press.

Molenaar, N.J. and J.H. Smit (1996). Asking and Answering Yes/no-questions in Survey Interviews: a Conversational Approach. Quality and Quantity 30: 11536.

Oppenheim, A.N. (1966). Questionnaire Design and Attitude Measurement. London: Heinemann.

Pool, J. and I. Pool (1971). The Use of Tape Recordings to Ascertain Response Errors in KAP Surveys: Niger, West Africa. Paper presented at the Annual Meeting of the Population Association of America, Washington, D.C., April, 1971.

Quandt, A. (1973). The Social Production of Census Data: interviews from the 1971 Moroccan Census. Doctoral dissertation, Department of Sociology, University of California, Los Angeles.

Sacks, H., E.A. Schegloff and G. Jefferson (1974). A Simplest Systematics for the Organization of Turn-taking for Conversation. Language 50: 696-735.

Schaeffer, N.C. (1991). Conversation with a Purpose-or Conversation? Interaction in the Standardized Interview. In: P. Biemer, R.M. Groves, L. Lyberg, N. Mathiowetz, S. Sudman (eds.) Measurement Error in Surveys. New York: John Wiley and Sons, pp. 367-91

Schaeffer, N.C. and D.W. Maynard (1996). From Paradigm to Prototype and Back Again: Interactive Aspects of 'Cognitive Processing' in Standardized Survey Interviews. In: N. Schwarz, S. Sudman (eds.) Answering Questions: 
Methodology for Determining Cognitive and Communicative Processes in Survey Research. San Francisco: Jossey-Bass, pp. 65-88

Schaeffer, N.C., D.W. Maynard and R. Cradock (1993). Negotiating Uncertainty: Uncertainty Proposals and Their Disposal in Standardized Survey Interviews. Draft paper presented at the annual meetings of the American Association for Public Opinion Research, St. Petersburg, Florida, May 1992, and at the meeting of the International Sociological Association Research Committee 25 (Sociolinguistics), June 1992, Nijmegen, The Netherlands.

Schaeffer, N.C. and S. Presser (2003). The Science of Asking Questions. Annual Review of Sociology 29: 65-88.

Schaeffer, N.C. and E. Thomson (1992). The Discovery of Grounded Uncertainty: Developing Standardized Questions about Strength of Fertility Motivation. Sociological Methodology 22: 37-82.

Schiffrin, D. (1987). Discourse Markers. Cambridge: Cambridge University Press.

Schober, M.F. and F.G. Conrad (1997). Does conversational interviewing reduce survey measurement error? Public Opinion Quarterly 61: 576-602.

Smit, J.H. (1995). Suggestieve Vragen in Survey-interviews: Voorkomen, Oorzaken en Gevolgen. PhD dissertation. Amsterdam: Faculteit der Sociaal-Culturele Wetenschappen, Vrije Universiteit.

Smit, J.H., W. Dijkstra and J. van der Zouwen (1997). Suggestive Interviewer Behaviour in Surveys: An Experimental Study. Journal of Official Statistics 13 (1): 19-28.

Stone, L. and G. Campbell (1984). The Use and Misuse of Surveys in international Development: An Experiment from Nepal. Human Organization 43 (1): 27-37.

Suchman, L. and B. Jordan. (1990). "Interactional Troubles in Face-to-face Survey Interviews." Journal of the American Statistical Association 85, 409: 232-41.

Sudman, S. and N.M. Bradburn (1982). Asking Questions. San Francisco: Jossey-Bass.

Thompson, L.V., M. Nawab Ali, and J.B. Casterline (1982). Collecting Demographic Data in Bangladesh: Evidence from Tape-Recorded Interviews. World Fertility Survey Scientific Reports 41 (December). Voorburg: International Statistical Institute, and London: World Fertility Survey.

Tourangeau, R., L.J. Rips and K. Rasinski (2000). The Psychology of Survey Response. New York: Cambridge University Press. 
van der Zouwen, J., W. Dijkstra and J.H. Smit (1991). Studying respondent-interviewer interaction: the relationship between interviewing style, interviewer behavior, and response behavior. In R. Biemer, R.M. Groves, L. Lyberg et al. (eds.) Measurement Error in Surveys. New York: John Wiley and Sons, pp.419-37.

Ware, H. (1977). Language Problems in Demographic Fieldwork in Africa: The Case of the Cameroon Fertility Survey. World Fertility Survey Scientific Reports 2. Voorburg, The Hague and London: International Statistical Institute and World Fertility Survey.

Weinreb, A.A. (2006). The Limitations of Stranger-Interviewers in Rural Kenya. American Sociological Review 71, 6 (December):1014-1039. 


\title{
Appendix: Transcription conventions*
}

\author{
falling intonation, not necessarily the end of a sentence \\ , low rising/continuing intonation, not necessarily between clauses \\ ? rising inflection, not necessarily a question \\ rising intonation, weaker than indicated by a question mark \\ - $\quad$ cut-off \\ $=\quad$ connecting talk \\ talk faster than surrounding talk \\ talk slower than surrounding talk \\ talk quieter than surrounding talk \\ YES talk louder than surrounding talk \\ \$ \$ talk while laughing/smiling \\ marked rising and falling shifts in pitch \\ (h) plosive quality \\ ::: extension of a sound or syllable \\ ( ) transcription doubt \\ (( )) analyst's comments \\ (1.0) timed intervals \\ (.) short untimed pause \\ hh audible aspirations \\ hh audible inhalations \\ so emphasis \\ [ ] overlapping utterances or actions
}

*Abbreviated from Gardner (1994), Jefferson (1984), and Sacks et al. (1974). 